\title{
La catalogación genérica colectiva
}

Concha Rioja López

Asesora Técnica del Servicio de Protección del Patrimonio Histórico

\section{Palabras clave}

Ley de patrimonio Histórico de Andalucía. Catálogo General del Patrimonio de Histórico de Andalucía. Inscripción específica. Inscripción Genérica. Instrumentos de Protección. Patrimonio Histórico Andaluz.

\section{Resumen}

En el artículo se trata de explicar el significado de la Inscripción Genérica en el Catálogo General del Patrimonio Histórico de Andalucía, como una fórmula de protección colectiva de los bienes culturales. Al mismo tiempo, se estabecen los antecedentes existentes en la legislación española que avalan y justifican dicha figura jurídica.

La Ley |/I99|, de 3 de julio, de Patrimonio Histórico de Andalucía, establece, además de los BIC, dos nuevos tipos de catalogación: la específica y la genérica. En principio ambas tienen para el bien sobre el que se aplica el mismo grado de protección salvo que la primera implica la redacción de unas Instrucciones Particulares, la delimitación de un entorno y la vinculación de bienes muebles.

Bajo la figura de catalogación genérica que tiene su desarrollo legislativo en el Decreto 19/1995, de 7 de febrero, por el que se aprueba el Reglamento de Protección y Fomento del Patrimonio Histórico, en sus artículos 7.2, 9, 10,1 1, 1 2 y 13 del Capítulo 2, pueden protegerse, jurídicamente, inmuebles, muebles y actividades.

El artículo 7.2 dice en concreto: "La catalogación genérica se podrá tramitar de forma individualizada para cada bien o colectivamente. La inscripción colectiva se referirá a bienes agrupados según ámbitos formados por provincias o conjuntos de municipios".

La creación de la figura de catalogación genérica colectiva supone la observación, por parte del legislador, corroborada por la praxis, de la existencia de bienes con unas características comunes por responder a tipologías (de estilo artístico, tecnológicas, de modos de explotación del medio) similares. En muchos casos la agrupación de bienes bajo una misma figura es necesaria para dar coherencia a los bienes en sí. Si elegimos, por ejemplo, un tramo de calzada romana no será tan significativo como si contemplamos la totalidad de vías conocidas que, de manera coherente, nos remitirá a la política territorial de la expansión del imperio en la Bética. Igual podríamos decir de modelos de explotación de recursos de ámbitos supramunicipales.

Por otra parte, responde a la posibilidad de que un solo expediente de protección abarque un mayor número de bienes con la consiguiente economías de medios que esto supone.

Este enfoque no es nuevo. Basta recordar decretos tales como el de 22-IV-49, 57I/63 y 499/73, o sea, los castillos que tengan más de 100 años, cualquiera que sea su estado de conservación, las piedras heráldicas, los rollos de justicia y las cruces de término, o los Decretos 449/1973, de 22 de febrero, por el que se colocan bajo la protección del Estado los hórreos o cabazos antiguos existentes en Asturias y Galicia, y el Decreto 29/1984, de 2 de agosto, por el que se pone bajo la protección de la Comunidad Autónoma de Castilla y León los hórreos y pallozas existentes en su ámbito territorial.

En la Ley 16/1985, de 25 de junio de Patrimonio Histórico Español además de asimilar los mencionados decretos (Disposición adicional $2^{a}$ ) incorpora, en una declaración conjunta, las cuevas, abrigos y lugares que contengan manifestaciones de arte rupestre (artículo 40.2).

Entre los motivos que han movido al legislador a afrontar la protección de manera conjunta para determinado tipos de bienes están la relativa abundancia, pero ya en proceso de desaparición, de determinadas tipologías, el reconocimiento a priori de unos determinados valores, normalmente ligados a conceptos tales como el cronológico (caso de los abrigos prehistóricos) y la evolución en el concepto mismo de Patrimonio.

Deteniéndonos en esto último y sin pretender hacer una historia exhaustiva, vemos que la evolución del concepto de Patrimonio Histórico ha ido de la obra única, antigua ' y artística a una concepción mucho más amplia que abarca la obra y el entorno humano referidos a los pueblos y no solo a los estamentos de poder. Concha Barrero resalta la novedad e importancia de la incorporación del valor cultural como definidor de la incorporación de un objeto al Tesoro Artístico, y señala que esta disposición se adelanta en el tiempo a los principios y criterios que va a desarrollar, a nivel internacional, la teoría de los bienes culturales, formulada por la Comisión Franceschini del parlamento italiano en 1966 y posteriormente desarrollada por Massimo Severo Giannini. En el contexto español, el Real Decreto-Ley de 9 
de agosto de 1926 supone una profunda renovación respecto a las normas anteriores $y$, sobre todo, la incorporación de conceptos y medidas de protección anticipadoras de la moderna tutela de los Bienes Culturales. No cabe duda que en esta mirada ha influido de manera decisiva o, mejor puede decirse, es producto del proceso de democratización general occidental que se ha extendido a la mayoría del planeta. Quizás uno de los campos que ha mostrado mejor este proceso es la historiografía que ha pasado de los grandes relatos épicos donde, prácticamente, solo tenían cabida las clases detentadoras del poder (político, económico, social o religioso) a la, no ya tan reciente, historia de la vida cotidiana. Es evidente que los valores que pueden barajarse en ese otro tipo de obras son otros: frente a la unicidad del palacio o el cuadro la multiplicidad que pueden ofrecer desde una tipología de viviendas a los procesos tecnológicos tradicionales o preindustriales; frente a lo antiguo conceptos como lo tradicional entendido como un hecho de raíz no cronológica si no como proceso asimilado, adaptado y transmitido individual (conocimientos) o colectivamente (rituales, tradiciones); frente a lo artístico la significación que el bien tenga en cuanto exponente de modelos de explotación de recursos (haciendas, cortijos) o como respuesta al medio ambiente (tanques, cisternas, aljibes). En este sentido el bien deja de concebirse como un valor en sí, lo que se ha traducido en la mayoría de los casos en su descontextualización y en los casos más afortunados en su preservación a través de su puesta en escena mediante el trazado de su entorno, para pasar a ser el exponente de procesos (históricos, urbanísticos, tecnológicos).

Por otra parte la necesidad de agrupación de bienes está presente también en algunas figuras de la actual legislación. Así las figuras de Conjunto Histórico, la de Sitio Histórico o la de Lugar de Interés Etnológico de nuestra legislación autonómica.

En un recorrido somero por las demás legislaciones del ámbito español vemos que la necesidad de protección legislativa a grupos de bienes se ha salvado de muy distintas maneras.

Algunas han utilizado la promulgación de la Ley para protegerlos como en el caso de Castilla-La Mancha?.

Otras, como la vasca ${ }^{3}$, crean figuras específicas, además de las consabidas de Conjunto o Sitio Histórico como la de espacio cultural; la de Baleares que lo denomina igual que la nuestra Lugar de interés etnológico 4 o la de Cantabria 5 o la Gallega 6 Lugar de interés etnográfico.

La estrategia de protección de bienes de forma colectiva parte en nuestro caso de una etapa previa de inventario que cubre un primer nivel de reconocimiento territorial y suministra la información suficiente para afrontar la elección del modelo de protección a seguir. En otros casos han sido necesarios informes previos específicos para superar esta primera etapa de evaluación.
Si, como hemos dicho, partimos del conocimiento suministrado por los inventarios, consecuentemente se está aplicando este modelo de intervención grupal-genérica colectiva- a aquellos bienes cuyos inventarios están ya realizados o bien en los que su ejecución está bastante avanzada. Hasta la fecha se hayan bastante avanzados los inventarios de Patrimonio Etnológico y el de Patrimonio Arqueológico.

Dichos inventarios, concebidos desde sus diseños originales, para la protección responden más a modelos de catalogación que a modelos que responden al mero inventario. Por tanto se adaptan perfectamente a lo requerido para la mencionada primera etapa evaluativa.

El contenido básico del expediente de inscripción genérica colectiva coincide con el de catalogación individualizada, si bien se puntualiza en el mencionado artículo 10.2 ii ) que "cuando se trate de inmuebles objeto de catalogación colectiva bastará la designación de las áreas afectadas mediante la delimitación de polígonos o sectores a partir de un punto determinado por sus coordenadas, así como una breve descripción del bien".

Dadas las características comunes de los bienes incluibles en una catalogación genérica colectiva y para evitar redundancias descriptivas la documentación técnica comprende dos partes:

- Una en la que, lógicamente, se describen aquellos aspectos comunes (justificación de la inscripción genérica colectiva y de la significación del conjunto de los bienes, descripciones del medio físico y de las tipologías, historiografía y datos etnológicos)

- Otra en la que se realiza el estudio individualizado de cada bien y que contiene datos sobre su denominación, delimitación (coordenadas), justificación de la delimitación, descripción, parcelas afectadas, estado de conservación y titulares y propietarios.

Hasta la fecha en Andalucía se ha aplicado este modelo de protección en dos casos de patrimonio inmueble. El primer caso ha sido la catalogación de I 45 elementos relacionados con la cultura del agua, en el Parque Natural de Cabo de Gata-Nijar.

El segundo caso ha abarcado la protección de 16 bienes inmuebles de la Arquitectura del Movimiento Moderno en Andalucía.

La coherencia interna de ambos grupos, que en sí forman un verdadero sistema, varía sin embargo. El elevado número de bienes agrupados bajo la inscripción de los 145 elementos de Cabo de Gata representa de manera inequívoca la lucha de un territorio, desde hace siglos en proceso de desertización, por captar, conducir, almacenar o extraer el agua y las variadas soluciones que el ingenio del hombre ha creado para tales fines. 
Por otra parte, los 16 bienes elegidos como los más representativos del Movimiento Moderno en Andalucía responden en su integración a las corrientes internacionalistas de este movimiento.

La inscripción genérica colectiva no elimina la posibilidad de que algunos de los bienes que la forman tengan otro tipo de protección. Puede ocurrir, por ejemplo, que cambien las circunstancias del medio en el que se encuentran y sea necesaria la delimitación de un entorno y la redacción de unas instrucciones particulares; puede ocurrir, en otros casos, que durante la realización de la investigación que dará lugar a la documentación técnica reglamentaria, se descubra la existencia de bienes muebles que es preciso vincularle a determinado inmueble.

En la actualidad se encuentran en programación para su inscripción en el Catálogo General del Patrimonio Histórico Andaluz como inscripción genérica colectiva los siguientes grupos de bienes:
- Elementos industriales relacionados con la actividad minera, de interés arqueológico de la provincia de Almería y Huelva.

- Yacimientos arqueológicos del Campo de Gibraltar, de la provincia de Córdoba, de la provincia de Granada, de la provincia de Jaén, de la provincia de Málaga y de los términos municipales de Lebrija, Marchena, Alcalá del Río, Coria y Las Cabezas de San Juan.

- Monumentos megalíticos de la cuenca minera, de la Tierra Llana, Sierra y Andévalo de Huelva,

- Molinos de la ribera de los Vélez.

- Fiesta de la Cruz en la provincia de Huelva.

- Jardines Históricos de interés patrimonial de la provincia de Cádiz.
1. Será la Real Cédula de 6 de junio de 1803, dictada por Carlos IV, en donde por primera vez nuestro ordenamiento jurídico establece el concepto de monumento, siendo, según Concepción Barrero Rodríguez, el "dato de la antigüedad... (el) eje sobre el que se asienta el concepto mismo de monumento en esta definición que de él se da en nuestro derecho". Esta fundamentación de la protección del patrimonio en el valor o categoría de lo "antiguo" pronto se verá superada al incorporarse en diferentes normas dictadas durante el siglo XIX los valores "histórico" y "artístico" como propiciadores de la protección dispensada a un bien.

\section{LEY 30-5-1990, núm. 4/1990}

Art. 23. 2. "Quedan incoados los expedientes para la declaración como bienes de interés cultural de todos aquellos molinos de viento existentes en el territorio de Castilla-La Mancha con una antigüedad superior a los cien años.
3. Quedan incoados los expedientes para la declaración como bienes de interés cultural de todas aquellas manifestaciones de arquitectura popular, como silos, bombos, ventas y arquitectura negra, existentes en el territorio de Castilla-la Mancha, con una antigüedad superior a los cien años."

4. LEY 3-7-1990, núm. 7/1990

Artículo 2..$^{\circ}$ I)c) Espacio cultural, entendiéndose por tal el constituido por lugares, actividades, creaciones, creencias, tradiciones o acontecimientos del pasado vinculados a formas relevantes de la expresión de la cultura y modos de vida del pueblo vasco.

5. LEY 12/1998, de 21 de diciembre,

6. LEY I |/|998, de 13 de octubre,

7. LEY 30-10-1995, núm. 8/1995 